\title{
Analysis on Catering Distribution Based on Ant Colony Algorithm
}

\author{
Zhang Lejian", a, Huang Zongxiang ${ }^{2, b}$, Ge Yide ${ }^{3, c}$ \\ ${ }^{1,2,3}$ Zhong Yuan University of Technology, Zhengzhou, 450007, China \\ a'Zhang1989@126.com, ${ }^{\mathrm{b}} \mathrm{Hzx} 15515 @$ sina.com, ${ }^{\top} Y$ dhom@sina.com
}

\begin{abstract}
Keywords: Catering distribution; Ant colony algorithm; MATLAB emulation; Improvement Abstract. This paper conducts an analysis on feasibility of catering distribution based on ant colony algorithm and mainly sets initial parameters for relative programs, such as ant colony scale (number of ants) $\mathrm{m}$, information element significance factor $\alpha$, heuristic function significance factor $\beta$, information element volatilization factor $\rho$, total information element releasing quantity $Q$, the maximum number of iterations, initial value of number of iterations. Based on the aforesaid, it establishes an emulation model based on customer satisfaction for the purpose of maximizing customer satisfaction and minimizing transportation cost and it applies MATLAB emulation to check and calculate distribution path. Result shows that adoption of ant colony algorithm will assist with reasonable distribution of transport capacity of restaurants and increase their profitability.
\end{abstract}

\section{Introduction}

As the internet is becoming more and more popular, taking-out market enters into a high-speed development era. Catering distribution resulting from it has become a protrudent problem. However, it is frequently thought to be high cost, slow distribution and not satisfied by customers[1-4]. Highly efficient catering distribution will not only accelerate speed of response to customer demands and improve service quality but also will reduce operation cost of catering service providers. However, traditional distribution is conducted by completely depending on subjective consciousness. Research on catering distribution process hasn't been conducted. User demands are scattered. Therefore, there are different demand distribution points in the whole distribution area[5-7]. When there are many takeouts arrived in a same period of time, it is necessary to determine where to start and where to end at the time of departing according to the area and location distributed. Or else, back-flow will be caused during distribution and waste will be caused thereby[8-9]. Therefore, the ant colony algorithm is adopted to conduct an analysis of the delivery path and improve it so as to choose an optimized path and achieve the goal of optimal path.

\section{Analysis on optimization of optimal routes of catering distribution}

\section{Case analysis of catering distribution}

It is necessary to confirm each location for meal delivery in optimization of catering distribution path, which is for the convenience of emulation. Select some areas to be objects of the emulation. Twenty locations are selected in total. Let's suppose that each location has demands, then it is necessary to determine an optimal route so as to make sure that food can be sent as fast as possible. Here below is the calculation of optimal route based on ant colony algorithm.

Calculate distance between each demand point: establish a coordinate system and mark coordinates of the 20 points to get a symmetrical matrix. It should be noted that the calculated element on the diagonal line of the matrix is 0 . But according to the aforesaid, heuristic function is $1 / \mathrm{d}$. Therefore, in order to ensure that the denominator is not 0 , it is necessary to amend the elements on the diagonal line. Here the number can be set to be very small, such as $10^{-4}$ and $10^{-5}$. 
Initialization of parameters: like what has been said in the previous section, some initial parameters, i.e. initialization of initial parameters are involved before the program is run. Refer to Analysis ofparametersinitialization, for parameter setting and its influence on simulation results.

Iterations to find the optimal route: firstly establish a solution space, in other words, various locations visited by each ant according to the transition probability formula. Then calculate the length of the path each ant passes by. And after each iteration, calculate and update, according to relevant formula, the information element concentration of the paths connecting two locations. Through continuous iterations and finding, keep records of the optimal path and length to find out the optimal path.

\section{Simulated analysis}

Use the MATLAB simulation software to run the ant colony algorithm simulated program to get the optimal route that is optimized as shown in Fig.1 below. What can be seen from the figure is that after going through all demand points, the optimal distance is $3,658 \mathrm{~m}$.

What is shown in Fig. 2 is the average distance and the shortest distance under various iterations conditions. What can be seen from the figure is that the average distance and the shortest distance declines continuously along with unceasing increase of the number of iterations. But after number of iterations reaches to 160 , the shortest path already tends to be stable and reaches to the final state. In other words, so far, the path has been the optimal path after the optimization at this time.

蚁群真法优化路径(最短距高: 吅吅口)

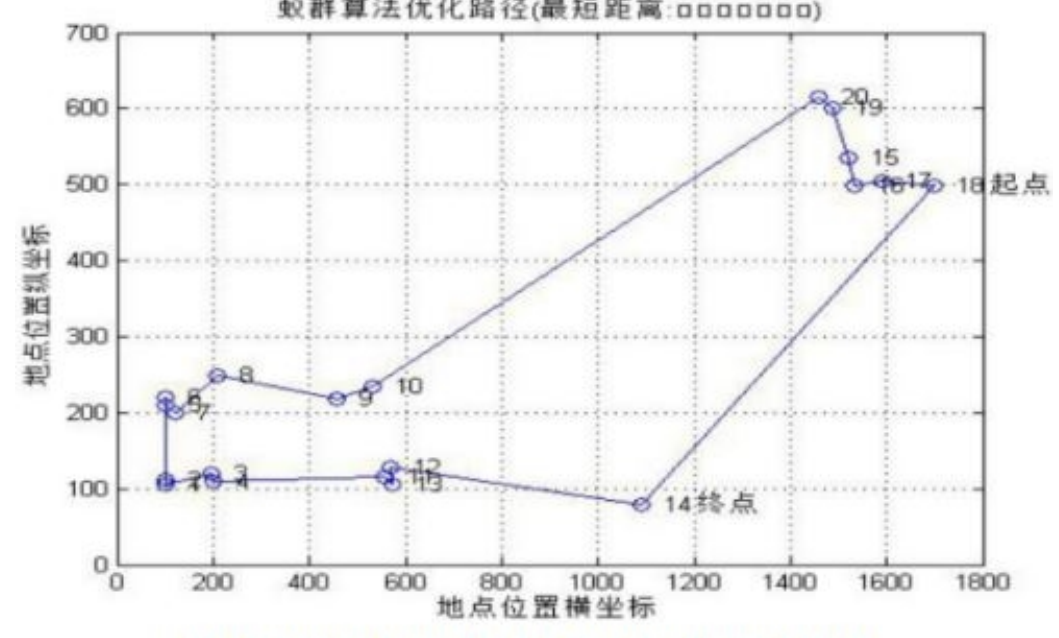

Fig.1 Ant Colony Algorithm Optimized Path

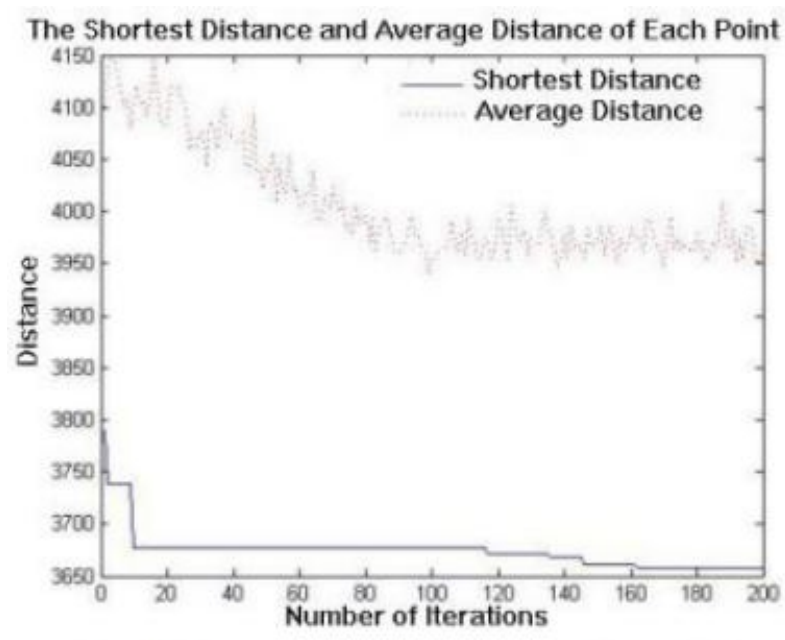

Fig.2 Comparison Between the Shortest Distance and Average Distance of Each Point

\section{Analysis ofparametersinitialization}

Effect of $\boldsymbol{m}$ on the result: in order to probe and analyze the effect of number of ants $m$ on optimal path, we compare with 5 different ant groups' optimal paths. Each group runs for 10 times, the result can be referred to Table 1 . Therein we can see that when there are 40 ants, the shortest average path is $3,659 \mathrm{~m}$. Meanwhile the shortest path value is $3,658 \mathrm{~m}$.

Table 1 Effect of Ant Quantity $m$ on the Optimal Path Unit: $m$

\begin{tabular}{|c|c|c|c|}
\hline Distance & $\begin{array}{c}\text { Average } \\
\text { value }\end{array}$ & $\begin{array}{c}\text { Maximum } \\
\text { value }\end{array}$ & $\begin{array}{c}\text { Minimum } \\
\text { value }\end{array}$ \\
\hline 10 & 3678 & 3682 & 3670 \\
\hline 20 & 3674 & 3682 & 3668 \\
\hline 30 & 3672 & 3680 & 3667 \\
\hline 40 & 3659 & 3662 & 3658 \\
\hline 50 & 3672 & 3688 & 3670 \\
\hline
\end{tabular}




\section{Effect of $\alpha$ and $\beta$ on the result:}

$\alpha$ refers to information element significance factor while $\beta$ refers to heuristic function significance factor. To study the effect of initial factors $\alpha$ and $\beta$ on optimal path, we compare with 5 different $\alpha$ and $\beta$ cases' optimal paths. Each group runs for 10 times, the Table 2 Effect of $\alpha$ and $\beta$ on the Optimal Path Unit: $m$ result can be referred to Table 2 .

Table 3 Effect of $\rho$ on the Optimal Path Unit: $m$

Effect of $\rho$ on the result :In order to study the effect of information element volatilization factor $\rho$ on the optimal path, we compare with 5 different factors $\rho$ to find out the optimal path. Each group runs for 10 times, the result can be referred to Table 3. Therein we can see that while $\rho=0$. 1, the shortest average path is $3,665 \mathrm{~m}$. Meanwhile the shortest path value is $3,661 \mathrm{~m}$.

Effect of $\mathbf{Q}$ on the result :To study the effect of total information element releasing quantity $\mathrm{Q}$ on the optimal path, we compare with 5 groups' $\mathrm{Q}$ to find out the optimal path. Each group runs for 10 times, the result can be referred to Table 4. Therein we can see that while $\mathrm{Q}=100$, the shortest average path is $3,663 \mathrm{~m}$. Meanwhile the shortest path value is $3,659 \mathrm{~m}$.

Seen from aforesaid analysis on initial data, different initial data bring different simulation effects. Based on each group data comparison, we can simulate an initial data with the best simulation

\begin{tabular}{|c|c|c|c|}
\hline Distance & $\begin{array}{c}\text { Average } \\
\text { value }\end{array}$ & $\begin{array}{c}\text { Maximum } \\
\text { value }\end{array}$ & $\begin{array}{c}\text { Minimum } \\
\text { value }\end{array}$ \\
\hline 0.1 & 3665 & 3670 & 3661 \\
\hline 0.2 & 3668 & 3675 & 3662 \\
\hline 0.3 & 3668 & 3679 & 3666 \\
\hline 0.4 & 3669 & 3683 & 3663 \\
\hline 0.5 & 3665 & 3672 & 3662 \\
\hline
\end{tabular}

Table 4 Effect of $Q$ on the Optimal Path Unit: $m$

\begin{tabular}{|c|c|c|c|}
\hline Distance & $\begin{array}{c}\text { Average } \\
\text { value }\end{array}$ & $\begin{array}{c}\text { Maximum } \\
\text { value }\end{array}$ & $\begin{array}{c}\text { Minimum } \\
\text { value }\end{array}$ \\
\hline 1 & 3677 & 3685 & 3670 \\
\hline 50 & 3669 & 3679 & 3663 \\
\hline 100 & 3663 & 3669 & 3659 \\
\hline 500 & 3678 & 3687 & 3665 \\
\hline 5000 & 3688 & 3695 & 3671 \\
\hline
\end{tabular}
improving effect.

\section{Conclusions}

Compared with traditional distribution mode, this case optimizes distribution routes by applying relevant technique to improve distribution efficiency. However, it is impossible to get the quantitative comparison of improving effects between current case and this case. Moreover, as an effective way to improve and choose optimal path, we can use the ant colony algorithm to choose the optimal route under certain assumptions. This is not only very important for the catering distribution, but also provides technical support for the distribution range expansion of taking-out market. 


\section{References}

[1] Tian Rui. (Co-author), Lin Lihua. (editor), Liu Zhanfeng. (editor), Lou Wenzhong. Logistics Engineering[M]. Beijing: Peking University Press, 2009.4

[2] Dai Enyong, Jiang Zezhi. and Yang Xiaohu. Logistics Strategies and Planning, Tsinghua University Press, 2014-3

[3] Hu Zongwu. Principles, Methods and Application of Industrial Engineering[M]. Shanghai: Shanghai Jiaotong University Press, 2003

[4] Chen Rongqiu and Ma Shihua. Production and Operation Management[M]. Beijing: China Machinery Industry Press, 2005

[5] Teaching Materials Writing Group of Operational Research. Operational Research (the $3^{\text {rd }}$ edition) [M]. Beijing: Tsinghua University Press, 2005.6

[6] Wu Qizong and Hou Fujun. Operational Research and Method of Optimization.[M]Beijing: China Machinery Industry Press, 2013.3

[7] Zhao Xiaochuan. MATLAB Picture Processing: Capacity Improving and Application Case[M]Beihang University Press, 2014.1

[8] S.C. Wheelwright and S.Makridakis: Forecasting Methods for Management, John Wiley \& Sons,Inc., New York,1990

[9] Dorigo M.Ant Algorithms and Atigmergy.Future Generation Computer Systems.2000.12(8) 